\title{
La comunidad ortopédica. Por una crítica de patologías desde el paradigma inmunológico
}

\section{The orthopedic community. For a criticism of pathologies from the immunological paradigm}

\author{
BORJA GARCÍA FERRER
}

Universidad de Granada

El espacio común de los encuentros, se encuentra él mismo en ruinas.Pero lo imposible no es la vecindad de las cosas, sino el sitio mismo en el que podrían avecindar.

M. Foucault

RESUMEN. Este trabajo explota el potencial hermenéutico de la dialéctica espositeana communitas/immunitas para indagar las raíces ontológicas del nuevo malestar en la cultura a tenor de los efectos antropológicos de la «hiperestimulación semiótica», así como sus expresiones mórbidas en la praxis sociopolítica. Desde esta perspectiva, analizamos los devaneos posmodernos de la identidad personal para determinar que, en su caso, el síndrome inmunitario del presente es inseparable del apogeo consumista, hasta el punto que constituye un epifenómeno de la fase posindustrial del Capitalismo.

Palabras clave: Malestar; Communitas; immunitas; Semiocapitalismo; identidad posmoderna.

\section{Introducción}

Si la filosofía está llamada, aun siendo errática, a instalarse en el centro donde la historia y la vida son advenimiento o sentido naciente, entonces no puede permanecer impasible ante el desafío que repre-
ABSTRACT. This paper makes use of the hermeneutical potential of the dialectics communitas/immunitas as developed by Espósito, in order to look into the ontological roots of the new uneasiness in culture according to the anthropological effects of «semiotic hyperstimulation», as well as its morbid expressions in the socio-political praxis. From this point of view, we analyze the postmodern dealings of the personal identity to establish that the immune syndrome of present time is inseparable from the heyday of consumerism, to such an extent that it has become an epiphenomenon of the post-industrial stage of Capitalism.

Key words: Uneasiness; Communitas; immunitas; Semiocapitalism; post-modern identity.

senta el nuevo malestar en la cultura y su rumor incesante, pues la alarmante proliferación de patologías sociales se funda en mecanismos y fuerzas ciegas que gobiernan desde la trastienda, la matriz oculta o el nomos, por hablar como Agamben, del espacio político que nos hospeda, de modo 
que atraviesa su organización material hasta conducirnos a la psicosis colectiva. Se trata, por tanto, de permanecer a la altura del acontecimiento en su enigmática ausencia de presencia, distanciarnos anacoréticamente de lo expresado para apreciar la profundidad tectónica del malestar, la inactualidad de la actualidad, lo invisible de lo visible.

Somos conscientes que la expansión trepidante de la sociedad de la información, el desarrollismo tecnológico y, en general, los nuevos rostros del Capitalismo reticular de la autonomía ilusoria, modifican el panorama de las dependencias y servidumbres humanas de tal manera que camuflan el malestar preponderante con las exuberantes máscaras de lo productivo y lo gratificante, hasta el prurito que hoy domina la tendencia de «cancelar y depotenciar los conflictos, escondiéndolos o aplazando su solución, [de forma que] el malestar circula clandestinamente, como algo que normalmente no queremos mirar de cerca» ${ }^{1}$. Pero precisamente por eso, juzgamos necesario que el pensador, parafraseando a Merleau-Ponty en su Elogio de la Filosofía, «despierte y hable» sobre las fuentes ontológicas donde hunden sus raíces las formas de malestar que malogran el espacio abierto de lo común en la actualidad, esto es, el suelo nutricio de la reflexión filosófica ${ }^{2}$.

En tal disposición de los términos, es de recibo realizar una aclaración conceptual y metodológica crucial para nuestros propósitos. La noción de malestar que manejamos no parte de un criterio absoluto de análisis, allende la lógica sustancialista y oposicional «normal-pa- tológico» que yace latente tras la tradición psicopatológica desde el mismo momento de su gestación. No se trata, desde esta óptica, de «anomalías» o «trastornos» psíquicos sino de «modos de ser» trans-individuales e inmanentes que, articulados en torno a nuestra íntima comprensión del mundo, configuran un malestar clandestino pero tácito, cuyo alcance erosiona la fisionomía de la vida en cuanto tal. De tal suerte que estamos abocados a comenzar ofreciendo una interpretación ontológica del «ser» de la existencia humana, pues ¿cómo, si no, entender su desfallecimiento?

Pero a pesar del carácter ontológico del malestar, no nos pasa desapercibido, a la luz de los datos recopilados por la Organización Mundial de la Salud, el extraordinario incremento experimentado por la tasa de incidencia psicótica en términos de enfermedades del vacío, cuyo tratamiento se cobra, por cierto, un oneroso tributo de las arcas en los gobiernos de los países, curiosamente, más desarrollados $^{3}$. En efecto, dado que el $m a-$ lestar de la civilización (plano ontológico) y sus síntomas mórbidos (plano óntico) convergen, según las consideraciones heideggerianas más elementales, como dos caras heterogéneas del acontecimiento $^{4}$, adoptaremos un enfoque epistemológico interdisciplinar, en aras de enriquecer, más allá de segmentaciones perniciosas y jerarquías quiméricas, la mirada holística de la filosofía sobre la sombra del malestar con el valor cognoscitivo de la ciencia empírica a la hora de contrastar patologías sociales específicas, como se sigue del concepto aristotélico de lógos. 


\section{La pregunta por la communitas}

Como queda dicho, el horizonte de nuestra investigación se cifra en la pregunta por el ser, con el objeto de examinar las implicaciones patológicas de la comunidad en el sentido de una ontología política crítica del presente. Ahora bien, la capacidad autodestructiva de la humanidad evidenciada, en términos de exterminio, por los totalitarismos del siglo $\mathrm{XX}$ en nombre de la comunidad cancela, como advierte Nancy en su celebrado Conloquium $^{5}$, cualquier posibilidad de comprender una articulación del ser-en-común según el modelo de un «ser» en general. Nos encontramos, así pues, en los confines de la tradición filosófica y política occidental, cuyo caudal de sentido y su fuerza connotativa han sido desbordados ya, toda vez que la oleada moderna comenzó su retirada, por las dinámicas contemporáneas, a pesar de los delirios etnógenos trasnochados por el efecto de indistinción en un proceso global donde la homogeneización infinita arrastra consigo cualquier signo de co-existencia.

$\mathrm{Si}$ bien es cierto que la naturaleza social del hombre constituye uno de los tópicos más cacareados en la historia de las ideas, la analítica existencial del «ser-ahí» (Dasein) en Ser y Tiempo se distingue por reubicar la problemática de la comunidad en unas coordenadas decididamente diferentes, por concurso de las cuales el seren-común afecta a nuestro ser en lo más profundo de su textura ontológica, más allá de la gastada «semántica del propium» donde descansa la noción metafísica de «comunidad» (sustancialista y subjetivista), conceptualmente vinculada a lo $\mathrm{co}$ - mún, entendido en términos de identidad, propiedad y pertenencia. Efectivamente, Heidegger redefine el mapa conceptual de la Modernidad (su ontología de lo pleno y lo cerrado) mediante su lúcido planteamiento sistemático del existenciario «co-estar» (Mitsein $)^{6}$, en virtud del cual el quién del «ser-ahí» no posee el carácter de la mismidad porque los otros están ya siempre co-existiendo en el estaren-el-mundo. Por tanto, el «ser-ahí» es esencialmente en sí mismo ser-con, o sea, el «con» (entendido existencial y no categorialmente) tiene su modo de ser, por lo que el mundo es un «mundo en común» (Mitwelt).

Bajo esta luz, Espósito realiza una revisión terminológica del vocablo «comunidad» ${ }^{7}$ que abre un nuevo horizonte de posibilidades gramaticales, retóricas, lógicas y filosóficas con vistas a rescatarla de las garras del fascismo (pero también de la marca blanca del europeísmo). Como Heidegger sugiere, el término "comunidad» designa el ser-en-común donde radica una existencia coincidente con la exposición a la alteridad, el entre (Zwischen) que nos vincula hasta en el apartamiento, aquello por lo que existimos en sentido enfático (en lo abierto, pero siendo la apertura misma, sin otro soporte que una relación $)^{8}$. El carácter abismal del ser implica, en este sentido, que nos encontramos ya arrojados en el terreno de lo impropio: «Nuestro socius por excelencia, nosotros mismos, es alter, es otro, que nos sorprende o seduce o captura o lacera, pero con el cual, sin embargo, co-habitamos irrevocablemente» ${ }^{9}$. Frente a la seguridad cotidiana del «estar en casa» (Zuhause sein), nuestra condición se cifra, desde 
esta perspectiva, en el desamparo (Unheimlichkeit), que no es el estado de ánimo del que está fuera de casa sino del que no tiene hogar (Heim), es decir, del «ser errático» ${ }^{10}$.

Ahora bien, ¿cómo traducir políticamente un discurso tan prolífero a nivel teórico? Con el afán de explorar su significación política, Espósito efectúa un desplazamiento genealógico en la reflexión sobre la comunidad que prolonga el «nihilismo propio» heideggeriano desde el ámbito del «cum» al del «munus», en la línea de una concepción sacrificial de los vínculos sociales. La triple acepción de «obligación» (onus), «función» (officium) y «don» (donum) que comprende la raíz latina de communitas pone de manifiesto que la condición de co-existencia de singularidades finitas se define por una carga, un deber o una tarea: el cuidado de la nada que nos acomuna y, por ende, el reconocimiento de nuestra incompletud radical. Se trata de nuestro «imperativo cenital», la invocación existencial irrecusable de estar a la altura de nosotros mismos $^{11}$.

\section{Immunitas y semiocapitalismo}

Sin embargo, la communitas encierra un carácter paradójico porque, a pesar de erigirse como nuestra inevitable morada, sólo es posible en la medida que incentiva aquello que la socava, a saber: el aislamiento y la prisión. En realidad, todas las formas de encierro que prescriben la vida en común atestiguan nuestra incapacidad de vivir en el afuera sin más, hasta el punto que la comunidad sólo tiene lugar si ha sido previamente esterilizada, cercada y ordenada entre las barreras protectoras de un enclave. De aquí la tendencia natural del hombre (entendido como homo habitans, en el sentido de Sloterdijk) a construir un hogar donde cobijarse de la amenaza que representan los peligros de la incertidumbre:

La ausencia de límites le salta a la garganta y lo estrangula con fuerza. Es esta experiencia dolorosa del abismo sin orden ni fondo lo que lo lleva a repeler continuamente el espacio infinito y a parapetarse detrás de las barreras materiales y simbólicas de su propia producción artificial. El hombre no crece y no prospera más que al interior de los límites que él mismo ha erigido como muros de fortaleza que lo protegen contra la indeterminación del afuera. El parcage es la solución práctica al terror paralizante de lo ilimitado. Encerrar [Parquer] a los hombres como a las bestias es confesar la urgente necesidad de autodomesticación ${ }^{12}$.

Si traducimos este pasaje al lenguaje espositeano, tenemos que la lógica expropiativa de la communitas demanda un suplemento (kathékhon) capaz de contrarrestar su deriva potencialmente tanática ${ }^{13}$ con la reconstrucción de la subjetividad en cuanto tal, a fin de asegurar el dominio de lo propio sobre toda intrusión amenazadora de alteridad. De aquí la lógica inmunitaria de la ingratitud:

Mientras la communitas es la relación que, sometiendo a sus miembros a un compromiso de donación recíproca, 
pone en peligro su identidad individual, la immunitas es la condición de dispensar de esa obligación y, en consecuencia, de defensa contra sus efectos expropiadores ${ }^{14}$.

Aunque resulta necesaria para conservar nuestra vida (de hecho, no existe comunidad sin aparato inmunitario o fantasía autodefensiva), como sabemos desde el siglo XVI gracias a Paracelso, toda inmunización en dosis elevadas conlleva, por hablar con Benjamin, el sacrificio de lo viviente por mor de la mera supervivencia, en tanto que clausura el sentido mismo de nuestra existencia. La immunitas es, desde este punto de vista, phármakon, veneno y remedio. Pues bien, si el sistema inmunológico constituye el síndrome de nuestro tiempo a costa de los vínculos comunitarios, es porque la deriva de sus fuerzas ha llegado a ser no sólo paradójica sino trágica, causando el mismo caudal de riesgo y muerte que pretendía conjurar ${ }^{15}$.

Antes de poner a prueba esta hipótesis, debemos considerar el papel rector que juega el Capital sobre la vida, hasta el extremo de constituirse como la única fuente de sentido socialmente válida. Como enseña Berardi ${ }^{16}$, la lógica capitalista implementa su invisible dictadura a través de la infoesfera, ese hipermundo de conectividad infinita cuyos dispositivos micrológicos determinan nuestro modus vivendi en el sentido del vértigo, la ansiedad, y la frustración. En verdad, no se trata tanto de una «administración de la vida» (biopolítica), como pensaba Foucault, sino de un «cuidado de la muerte» (tanatopolítica). Y es que con tal de mantenernos eternamente disponibles, cual correa de transmisión, en la movilización de las consignas, el Capitalismo tardío pone en marcha un «bombardeo semiótico» que nos aboca al pánico y la desorientación, pues su «profusión lujuriosa» de estímulos sin ligazón satura nuestra atención de manera tal que rebasa, a la velocidad de la luz, los límites individuales:

Podríamos expresarlo así: primero está cada uno concentrado, comprimido en su trabajo $\mathrm{y}$ en las restantes actividades de la vida; cuando cesa esa presión, en el llamado tiempo libre, los liberados de la presión estallan y se precipitan en mil imágenes de acontecimientos que, propiamente, no los afectan. En verdad son las imágenes las que se precipitan sobre ellos. (...) Estímulos que de suyo son ocasionales, se disponen de forma duradera y buscan ocasiones siempre nuevas ${ }^{17}$.

Las relaciones se transmutan, entonces, en exógenas, al servicio de mandatos anónimos pero lo suficientemente amplios y holgados para reunir soledades en el «anillo férreo del terror», que mantiene a los átomos sociales tan estrechamente ligados como si su pluralidad se fundiese en un único hombre de dimensiones gigantescas ${ }^{18}$. No obstante, los flujos semióticos bloquean y desbordan la posibilidad de comunicarse porque, en la medida que poseen un carácter detonante (flash) y, a su vez, son tendencialmente infinitos hasta alcanzar el rumor blanco de lo indistinguible, lo irrelevante y lo indescifrable, no permiten discurrir sobre ellos:

El círculo de los sentidos, ampliado artificialmente a través de la prótesis me- 
diática, se ha desligado por completo del círculo de la acción. Ya no podemos reaccionar de forma adecuada a través de la acción, ni somos capaces de traducir el estímulo en acción y de darle salida a través de ella ${ }^{19}$.

Por su parte, los receptores humanos tratan en vano de elaborar y procesar semejante caleidoscopio abigarrado de pseudosignificados difusos mediante procesos de sobreinclusión (conexiones a-significantes, espirales asociativas, etc.) que desembocan en patologías sociocomunicativas de cuya amenaza no podemos ya librarnos, pues siempre están ahí, al acecho. El cibertiempo marca un límite infranqueable para la elaboración emocional con los otros, y todo lo somete al vértigo del decir y del contar, ese «éxtasis de la comunicación $»^{20}$ que unifica el espacio, a pesar de su apariencia polifónica, en un sólo eco siniestro, con menoscabo del sentido:

El problema no es de pérdida de sentido, sino del demasiado sentido, del too much. (...) Hay una proliferación de expresión, de dar expresión a todo (...). Eso para mí es la muerte del sentido, pero por exceso de sentido, y no por falta ${ }^{21}$.

En este contexto, el rumor desenfrenado de las «habladurías» (esto es, la «charla» como degradación de la palabra ${ }^{22}$ reduce todo lo esencial en la masa amorfa de una indiferenciación, en virtud de la cual los otros ya no comparecen ante nosotros como «objetos de solicitud» (Fürsorge) sino como sujetos que «flotan en el vacío». Nuestro estilo de vida, visto así, es trágico por partida doble: entre el hombre de masas, que suspira por un poco de intimidad, y el náufrago, que añora a sus congéneres en la soledad de su isla:

El ser en la tentación se encuentra (...) triturado por la doble tenaza de la nada. Si no se comunica se aniquila (en ese vacío que es la vida que se aísla). Si quiere comunicarse, se arriesga igualmente a perderse ${ }^{23}$.

En la sociedad hipercomunicada, el sistema inmunológico responde a la mecánica disolutiva de la «semiotización» en curso reprogramando el virus desestabilizador de nuestro metabolismo social, es decir, canalizando las réplicas de su «material genético» desde la degeneración hasta una terapéutica de los vínculos sociales basada en la reconstrucción de los límites individuales. Efectivamente, las últimas investigaciones inmunológicas en medicina y bioquímica establecen que un sistema inmune no sólo se caracteriza por la pericia de los anticuerpos a la hora de identificar y asesinar intrusos sino, ante todo, por su capacidad para definir positivamente un «yo».

\section{La constitución ortopédica de la identidad}

Fernando Bayón traduce sociológicamente la retórica médica de la inmunidad y resume la nueva inmunología para una identidad posmoderna con el siguiente biolema: «Sólo en cuanto extraño puede algo volverse propio» ${ }^{24}$. Lamentablemente, el viejo «yo» ha evolucionado en la única dirección que permiten las formas de encie- 
rro por excelencia de nuestra época, a saber, los centros comerciales. En este desconcertante proceso, la docilidad que nos socializa transforma nuestros cuerpos, al ritmo que marcan la «consumopatía» ${ }^{25}$ y la «avidez de novedades» ${ }^{26}$ concomitante, en una «interfaz caliente y membranosa de comunicación, mientras la carne se torna porosa, híbrida, comercial, blanda, transaccional, quirúrgica y ampliable». De aquí nuestro sino: «Un grafito calcado sobre la piel, alternativamente, de las periferias y los centros comerciales en las ciudades hip-hop del capitalismo de marcas. Como dicen los Violadores del Verso: "Vengo de otro sitio donde nunca he estado" $\gg{ }^{27}$.

Observada más de cerca, no cabe duda que la identidad posmoderna abandona la consabida exigencia de autenticidad por la que Heidegger aboga, en Ser y Tiempo, contra el hombre-masa, en la medida que su tipo ideal despliega, en su forma más pura, la propiedad de la maleabilidad:

Se caracteriza por la posesión un "yo modular" (modular me), fácilmente ensamblable a la manera de un meccano, de un yo dossier obtenido por el apilamiento de muchos otros (feuillettage) o de un yo patchwork, similar a una manta formada por la costura de múltiples retazos diferentes de tejidos ${ }^{28}$.

De hecho, el cuerpo nunca es original sino que se retuerce, a través de incontables amputaciones y trasplantes, en infinitos nudos inextricables y extraños circuitos (strange loops), arenas movedizas por donde fluctúa a la deriva, en la metáfora de Bauman, su «vida líquida», donde la velocidad (y no la duración) es lo que importa: «Una vida nómada, siempre sumida en un gerundio reestructurador que nunca culmina en nada, un trabajo sisífico que no puede detenerse en una configuración estable, un vaivén vital, una licuefacción trashumante que no puede permitirse ninguna solidez arraigada ${ }^{29}$.

La novela psicológica de la vida privada se reduce, en este contexto, a un agregado deshilachado de episodios y fragmentos heterogéneos, bajo el signo de una inmensa «socioplastia» que reconduce la cuestión de la identidad personal hacia la «ambigüedad» o «teatralización» de la vida ${ }^{30}$ y el mundo como «espectáculo» ${ }^{31}$, mientras instituye lo alógeno como prótesis (potencialmente desechables) al amparo de la reconstrucción de una personalidad mejorada ${ }^{32}$, sin hacer balance ni asumir responsabilidades:

Desde la perspectiva de este nuevo modelo de excelencia, la permanencia y sobre todo la permanencia de uno mismo o la adhesión duradera a unos «valores» son criticables como rigidez incongruente, incluso patológica y, dependiendo del contexto, como ineficacia, mala educación, intolerancia o incapacidad de comunicación ${ }^{33}$.

En resumen, podría decirse que la Posmodernidad se define por el reciclaje, su médium es el video tape y su material, el plástico biodegradable. No es producto de la casualidad, vistas las cosas así, que el trastorno de personalidad múltiple sea la enfermedad mental más pujante de nuestra era.

Desde esta óptica, Sloterdijk convierte la figura del «traje espacial» en una metá- 
fora que permite distinguir las implicaciones patológicas de la dialéctica inmunitaria en la Posmodernidad cyborg, toda vez que la necesidad de preservación termina contradiciendo la salud de su desarrollo por tomarse de forma exclusiva y excluyente respecto a la apertura de la existencia que responde al nombre de communitas. En el afán por ensamblar la identidad con jirones consumibles, intercambiables y transitorios, buscamos volver familiar un entorno que, en principio, nos resulta extraño. Sin embargo, paradójicamente, las prótesis del «yo» terminan circunscritas a la propia piel, de modo que el único vestigio de propiedad se cifra en nuestro «traje espacial». La búsqueda de lo propio acarrea, entonces, la máxima impropiedad:

El hombre de nuestro presente, ya no muestra esa gallardía cenital capaz de mantener en franquía el entre. Más bien, (...) lo anega continuamente. Vierte sobre el intersticio todas sus miserias, convirtiéndolo en un lugar de muerte, (...) una fosa reticularmente esparcida a lo largo y ancho de la tierra ${ }^{34}$.

Se trata de una re-biologización del campo antropológico que supone el desfondamiento del bios (entendido aristotélicamente como nuestra forma de vida específica, la «vida buena»-to eu zen-, cualificada en su anhelo de socialidad y expresión pensante en el ágora,), no ya en pro de la zoé (vida biológica o reproductiva) sino que la animalización de la comunidad política apunta directamente, parafraseando a Agamben, hacia la «nuda muerte», en detrimento de la ilustre idea de humanitas que ha patrocinado la tradición:

Considerada durante siglos como aquello que sitúa a los hombres por encima de la simple vida común a las otras especies, y cargada además, precisamente por ello, de valor político, no deja de adherirse cada vez más a su propia materia biológica. [Entonces,] (...) la humanidad del hombre queda necesariamente expuesta a aquello que puede (...) aniquilarla ${ }^{35}$.

\section{Implicaciones patológicas}

Pese a la pretensión narcisista de existir e insistir como ipse o, en los términos patentados por Negri y Hardt, «centros soberanos», el ocaso de la communitas no implica, en cualquier caso, su disolución, pues «nos llama con una voz que no podemos dejar de oír porque nace de nosotros mismos $»{ }^{36}$. Se trata, bien pensado, de su desfallecimiento, que conlleva múltiples patologías autoinmunes de superficie. Por decirlo con Heidegger: «También cuando un determinado Dasein fáctico no se vuelve hacia otros, cuando cree que no necesita de ellos o cuando, por el contrario, los echa de menos, es en el modo del co-estar ${ }^{37}$. De hecho, la fragilidad de las identidades ortopédicas, siempre sometidas al estrés de la contingencia y la diseminación de sus bordes, indica que, lejos de caracterizarse por la consistencia de un uniforme militar, nuestro «traje espacial» constituye el margen, delicado y problemático, pero siempre permeable, de sus relaciones con aquello que, por definición, lo atraviesa y altera. 
¿Cómo evaluar dicha relación desde la óptica de una crítica de patologías? La disposición inconfesada de reforzar y optimizar hasta el paroxismo nuestro «traje espacial» va en detrimento del plano de lo ajeno, hasta el punto que el ego social se ha convertido definitivamente en una pluralidad disociada. Ciertamente, la ausencia de vínculos unitarios en la urdimbre reticular que nos sostiene viene motivada por la sacralización, en función de proteicas figuras fragmentadas, de las transacciones psicológicas, al abrigo de los mercados de pertenencia, las agencias del marketing y sus «identidades prefabricadas $\rangle^{38}$. La ideología cyborg rinde culto, de este modo, al mesianismo de la cirugía y sus virtudes ortopédicas, mientras repugna subliminalmente, en rigurosa proporción, todo lo que lleve la etiqueta del Estado ${ }^{39}$. En este sentido, la nuestra es una sociedad de idiotas, ya que sus ciudadanos, como refleja la acepción etimológica del término, hacen caso omiso de los asuntos públicos por mor de la expansión egocéntrica del espacio individual: «A la altura del presente, las jaulas o los anillos nos han idiotizado a la mayoría $»^{40}$.

Como envés de la misma moneda, la nada que nos co-liga invisiblemente ya no teje, en el orden del espacio público viviente, el vínculo de una vida superior e inmortal entre sujetos ${ }^{41}$. Cuando el recambio cuantitativo de lo mismo oculta en absoluto, por-lo-que-sea-y-al-precio-quesea, la imposibilidad de «ser uno mismo» en pos de una identidad articulada por diferencias cada vez más aparentes, el «mundo de la vida» deviene pura transitoriedad sin contenidos ${ }^{42} \mathrm{y}$, como consecuencia de ello, las relaciones interperso- nales se tornan accesibles, fugaces y superficiales, desinfectadas de los riesgos implícitos en sus efervescencias y mestizajes. En este contexto, cada individuo trata de establecer los vínculos que le interesan y con las personas de su elección ${ }^{43}$, mientras que el valor de un contacto es directamente proporcional a su carácter imprevisible, en detrimento de valores como el compromiso o la confianza. Por su parte, el fenómeno del encuentro (en el sentido de Binswanger) y, en general, los vínculos grabados por la inclinación recíproca y la correspondencia están siendo carcomidos por la «distancialidad» (Abständigkeit), ese cuidado obsesivo de una diferencia frente a los otros por la omnipresente conminación a «ser alguien»" que conlleva una atmósfera competitiva y enajenante $^{45}$. Ahora bien:

La distancialidad se funda en el hecho de que el convivir procura como tal la medianía [Durchschnittlichkeit]. (...) Todo lo originario se torna de la noche a la mañana banal, cual si fuera cosa ya largo tiempo conocida. Todo lo laboriosamente conquistado se vuelve trivial. Todo misterio pierde su fuerza ${ }^{46}$.

Hubo de pasar largo tiempo para entender cabalmente semejante misiva. El mérito es de Sloterdijk, cuando define la Posmodernidad como «posextremismo». Si el fin de los afueras inhóspitos decreta una vuelta a las situaciones medias, la organización compulsiva de la apariencia es la pauta de la mediocritas siglo XXI.

Con todo, la paradoja del ermitaño demuestra que, por mucha lejanía que construya alrededor para triunfar en su aisla- 
miento, nunca logra sustraerse del otro por completo, aunque sea bajo la forma deficiente de la nostalgia (Heimweh). Por ejemplo, uno de los signos ortopédicos más acusados del presente es la proliferación de prótesis de la espera (teléfono móvil, $m p 4$, ipod, etc.) a modo de ansiolítico contra la incomodidad que suele invadirnos, toda vez sometidos a la exigencia de transparencia establecida, en la visibilidad pública. Las NTIC expresan, empero, cierta melancolía por una comunidad ausente, como atestigua la herramienta del blog cuando nos servimos de ella para arrojar la intimidad del momento a la red con la esperanza de encontrar algún afín. Lamentablemente, también el entorno web termina satisfaciendo la dialéctica inmunitaria en su capacidad para ofrecer la ilusión de un vínculo al que aferrarnos:

La $w w w$ sólo puede extenderse si deja que sus flujos se llenen de nichos. El oxímoron se reproduce por doquier: en Internet, los blogs devienen en chats y los chats se autodenominan "rincones", $\mathrm{y}$ así las ventanas flotantes que nos prometen la apertura global van privatizando los encuentros redirigiéndolos hacia el sempiterno café del vis a vis. La red es hoy un parque temático de la familia ${ }^{47}$.

Desde una perspectiva más amplia, la absorción de la lógica de la red por la lógica doméstica refleja el carácter ambiguo que ostenta la célebre profecía mcluhiana de la «aldea global», a saber, la perfecta solidaridad entre globalización y aldeanización de la existencia: "Cuanto más interconectados estamos en la telemática red global, más nos replegamos en la inmanencia intimista de los reductos aldeanos $»^{48}$. Entretanto, los entornos urbanos situados entre la red evanescente de cosmopolitismo abstracto y nuestras aldeas se truecan desiertos peligrosos poblados por fantasmas, de cuya amenaza buscamos refugiarnos en la nueva ágora electrónica, ese «no-lugar» donde todo es falso, pues no es más que un pretexto para calentarse; allí donde nada puede suceder, porque nos empleamos sordamente a tiritar con los otros.

No obstante, las aldeas contemporáneas, esos receptáculos inmunitarios, no son familiares ni hogareñas, pues en la medida que modifican sus condiciones vertiginosamente, nuestra adaptación a la urbe telemática es siempre provisional y precaria, en un marco heteróclito de circulación, ventilación y conexión fugaz donde los lazos comunitarios discurren por caminos impersonales, mecánicos y abstractos, con menoscabo de la cálida unidad orgánica de la tierra, la íntima pertenencia o la comunión espontánea. Visto así, el resurgimiento del nacionalismo no constituye, a tenor del debilitamiento de los Estados modernos a manos del libérrimo Mercado (autorregulador y omnipotente), un fenómeno irracional y atávico desatado por oscuros prejuicios tribales, como nos vende la ideología neoliberal dominante, sino que responde a un exceso de nostalgia que llega hasta el extremo de la desesperación por abrazar una identidad donde agazaparnos (vale decir, inmunizarnos) del desarraigo, aunque sea en una inmanencia cultural arcaica y obsoleta. 


\section{Conclusiones}

En el empeño por conquistar, en la jungla de la infoproducción capitalista, una delimitación marcada por un modo de estar de carácter doméstico (es decir, arropado por afinidades duraderas, vínculos recurrentes y fidelidades previsibles), el sistema inmunológico termina convirtiendo la retícula de intersticios que podría ponernos en relación por mor de nuestra diferencia en una «fosa reticular» donde la posibilidad de decir «nosotros» se desvanece en un «yo» tambaleante, en estado de semi-ruina pero flexible y adaptable ad infinitum, mantenido por la tensión hacia una curación apócrifa que comparten todos los átomos sociales al abrigo del Capital y su fúnebre lógica, principio y fin. En esta inquietante encrucijada, avanza el caballo de Troya favorito de Occidente, a saber, la inaguantable antinomia entre individuo y grupo.

No se trata, por desgracia, de una integración graduada del agente patógeno mediante dosis preventivas, sino que la inteligente «lógica de lo mismo» de la inmunología médica tradicional conoce hoy rupturas y complementos de toda clase, en nombre de un pseudosujeto funcional con las condiciones de vida determinadas por el Capital en su actual fase ultraconsumista: la movilidad inconsistente, la fragmentación descentrada, la incertidumbre estructural, la ligereza vaporosa. Si la Posmodernidad se define, en palabras de Jameson, como la «lógica cultural» del Capitalismo, es porque penetra nuestra esencia hasta tal punto que formamos parte constituyente, en cuanto «capitales productivos» $\mathrm{o}$ 《recursos humanos», de su proceso interno, de tal suerte que rendimos pleitesía incondicionalmente a una marea ingobernable de fuerzas que nos gobiernan, refrescantes géneros de apariencia cuyas procelosas aguas no devuelven imagen alguna cuando nos miramos en ellas, velocidades infinitas, caprichosas e impredecibles que se confunden con la nada incolora que recorren, sin naturaleza ni pensamiento. Y es que como la oferta de bienes es ilimitada por naturaleza en el contexto capitalista, el deseo es estimulado hasta convertirse en insaciable.

De aquí la función estructural (cada vez más necesaria para la configuración y colonización de nuestros apetitos más íntimos) que cumple la innovación en el polícromo escaparate del mundo-supermercado $^{49}$ y la concomitante constitución posmoderna de la identidad como crisis perpetua y modulada, en su plasticidad, por una multiplicación ampliada exponencialmente de retales apenas entretejidos, objetos prêt-à-porter, de usar y tirar, funcionalidad ambigua y consistencia dudosa. Pues la revolución permanente que nos impone exige mostrarse lo bastante maleable para circular por distintos universos cambiando de propiedades, en lo que constituye una extensión de la lógica del préstamo temporal de las propiedades materiales a los atributos personales, toda vez sustraídos de su carácter permanente. En este sentido, la organización compulsiva de la apariencia reproduce por doquier, bajo la égida de la «socioplastia» contemporánea, la ocupación del «mundo de la vida» a manos de la mercancía, dando lugar a un deslizamiento del tener al parecer.

La celebrada libertad posmoderna para elegir (previo pago) nuestra forma de vida 
designa, desde este prisma, una dependencia sistémica, en la medida que obedece a una producción hiperbólica de demanda diversificada por una misma mercadotecnia con la capacidad de generar cierta ilusión de autonomía ${ }^{50}$ cuando, en verdad, nos proyecta inexorablemente en la única dirección del homo oikonomicus, pese a la aparente promiscuidad de modas y estilos a la venta en el psicodélico hipermercado social ${ }^{51}$. Porque, bien mirado, el ser sólo puede ser pensado como indeterminación por un sujeto poderoso, capaz de moldearlo con sus propias manos. Y esa forma de conciencia sólo aparece en el Capital, con su tremendo poder para arruinar el mundo o recrearlo como un demiurgo arbitrario.

Al servicio de la tanatopolítica capitalista y su estructura de dominio, silenciosa pero depredadora, el afán inmunitario nos ha convertido en representantes de nosotros mismos, ese extraño comercio por una personalidad que, finalmente, se parece demasiado a una amputación. El discapacitado constituye, en efecto, el prototipo de ciudadanía actual. Pero los terrenos de la identidad personal no son la única conquista del Capital sino que también logra apoderarse lóbregamente de nuestras estructuras sociopolíticas para imponer una totalización oikonomica sobre sus intersticios. En su condición de metarrelato configurador, el Mercado Absoluto, ese «nuevo Ídolo», fagocita y absorbe el espacio público de manera que impersonaliza, toda vez reducidas a transacciones abstractas y solipsistas, el significado coherente de las relaciones humanas, cuyos lazos adoptan la apariencia de meros encuentros consecutivos. Y es que lejos de tejer vínculos consistentes, el síndrome consumista se diluye en una ausencia relacional determinada por el tráfago, veloz y anárquico, de las mercancías que nos constituyen a modo de extensions of man. Emancipados de todo ropaje sociopolítico y sin más asideros donde agarrarnos, la communitas se reduce al conjunto de prótesis contratadas al precio de la identidad, mientras la sociabilidad circula por innumerables esferas de pertenencia, discontinuas y provisionales, cuya falsedad no roza los problemas reales del afuera.

\section{BIBLIOGRAFÍA}

Alba Rico, S., «Egolatría», Rebelión (2005)

[http://rebelion.org/noticia.php?id=20084]. Alonso-Fernández, F., Formas actuales de neurosis. Madrid: Pirámide, 1981.

Alonso-Fernández, F., Las nuevas adicciones. Madrid: Tea, 2003.

Arendt, H., Los orígenes del totalitarismo. Madrid: Alianza, 2004.

Bataille, G., Sobre Nietzsche. Voluntad de suerte. Madrid: Taurus, 1989.
Baudrillard, J., La ilusión y la desilusión estéticas. Caracas: Monte Ávila, 1997.

Bayón Martín, F., «La sociedad extrañada: Retóricas de la inmunidad», en Arribas Verdugo, S., Cano Cuenca, G. y Ugarte Pérez, J. (eds.), Hacer vivir, dejar morir. Biopolítica y capitalismo. Madrid: Arbor, 2010, pp. 247-272.

Bégout, B., Le ParK. París: Allia, 2010. 
Berardi, F., La fábrica de la infelicidad. Madrid: Traficantes de sueños, 2002.

Bodei, R., Destinos personales. La era de la colonización de las conciencias. Buenos Aires: El cuenco de plata, 2006.

Bodei, R., El doctor Freud y los nervios del alma. Filosofí y sociedad a un siglo del nacimiento del psicoanálisis. Valencia: Pre-Textos, 2001.

Boltanski, L. y Chiapello, E., El nuevo espíritu del capitalismo. Madrid: Akal, 2002.

Cacciari, M., El archipiélago. Figuras del otro en Occidente. Buenos Aires: Eudeba, 1999.

Comité Invisible, «Primer cerco. "I am what I am"», Espai en Blanc, 3-4 (2007) [http://www.espaienblanc.net/Primercerco-I-AM-WHAT-I-AM.html].

Debord, G., La sociedad del espectáculo. Valencia: Pre-textos, 1999.

Díaz Galán, J. «"Planet terror”: Esbozo para una tanatopolítica», en Arribas Verdugo, S., Cano Cuenca, G. y Ugarte Pérez, J. (eds.), Hacer vivir, dejar morir. Biopolitica y capitalismo. Madrid: Arbor, 2010, pp. 223-245.

Espósito, R., Bíos. Biopolítica y filosofia. Buenos Aires: Amorrortu, 2006.

Espósito, R., Categorías de lo impolítico. Buenos Aires: Katz, 2006.

Espósito, R., Communitas. Origen y destino de la comunidad. Buenos Aires: Amorrortu, 2003.

Espósito, R., Diez pensamientos acerca de la política. Buenos Aires: FCE, 2012. Heidegger, M., «QQué es metafísica?», en $\mathrm{Hi}$ tos. Madrid: Alianza, 2000, pp. 93-108.

Heidegger, M., «La constitución onto-teo-lógica de la metafísica», en Identidad y diferencia. Barcelona: Anthropos, 1988, pp. 99-158.
Heidegger, M. La proposición del fundamento. Barcelona: Serbal, 1991.

Heidegger, M., Ser y Tiempo. Madrid: Trotta, 2012.

Horkheimer, M. y Adorno, T. W., La dialectique de la raison. París: Gallimard, 1974.

Luckmann, T. y Berger, P., «Social Mobility and Personal Identity», European Journal of Sociology, V, 2 (1964), pp. 331-344.

Marcuse, $H$. , «La relevancia de la realidad», en Bontempo, Ch. y Odell, J. (eds.), La lechuza de Minerva. Madrid: Cátedra, 1979, pp. 235-247.

Marx, K., Contribution à la critique de léconomie politique. París: Éditions Sociales, 1957.

Ortega y Gasset, J., El tema de nuestro tiempo. Madrid: Espasa Calpe, 1943.

Polo Blanco, J., «Postmodernidad consumista y nihilismo de la mercancía», Éndoxa: Series Filosóficas, 23 (2009), pp. 309-357.

Sáez Rueda, L., «Enfermedades de Occidente. Patologías actuales del vacío desde el nexo entre filosofía y psicopatología», en Sáez Rueda, L., Pérez Espigares, P. y Hoyos Sánchez, I. (eds.), Occidente enfermo. Filosofia y Patologias de Civilización. Múnich: Grin, 2011, pp. 71-92.

Sáez Rueda, L., «Ficcionalización del mundo. Aportaciones para una crítica de $p a-$ tologías sociales», Revista de Filosofia Universidad de Costa Rica, XLV, 115116 (2007), pp. 57-69.

Sáez Rueda, L., Ser errático. Una ontología crítica de la sociedad. Madrid: Trotta, 2009.

Sáez Rueda, L., «Thanatología del neoliberalismo en el siglo XXI», Otros Logos. Revista de Estudios Críticos, 3 (2008), pp. 12-33. 


\section{Safranski, R., ¿Cuánta globalización pode-} mos soportar? Barcelona: Tusquets, 2004.

\author{
Schumpeter, J. A., Capitalismo, socialismo \\ y democracia. Folio: Barcelona, 1984.
}

\section{NOTAS}

${ }^{1}$ Bodei, R., El doctor Freud y los nervios del alma. Filosofia y sociedad a un siglo del nacimiento del psicoanálisis. Valencia: Pre-Textos, 2001, pp. 42-43.

${ }^{2}$ Nuestra investigación pretende rescatar de la «superfluidad», en la era de la especialización y las instituciones, la dimensión terapéutica de la filosofía para repensarla en el presente, contra el yugo ejercido a escala planetaria por la medicina clínica en el «arte de curar» desde la eclosión de la ciencia moderna y sus exigencias reductivas. Contamos, no obstante, con referentes ineludibles al respecto: la desvalorización de la vida afirmativa por mor del desierto donde se solazan inercia y «voluntad de nada» (Nietzsche), la «molarización» de la ex-tradición nomadológica hacia tierras ignotas (Deleuze), la colonización del «mundo de la vida» (Lebenswelt) por la razón estratégico-instrumental (Escuela de Frankfurt), el triunfo de la instalación manipulable del mundo (Heidegger), las ínfulas del pensamiento identitario (Derrida) o los dispositivos de poder que nos secuestran en el adiestramiento (Foucault). Asimismo, la crítica filosófica de la salud occidental ha sido asumida con éxito por notables «médicos de la civilización» en el siglo XXI, como demuestran los resultados del Proyecto de Investigación I + D La filosofia como terapia social, del cual nos sentimos deudores [http://www.ugr.es/ filosofiayterapia/].

${ }^{3}$ Cfr. Sáez Rueda, L., «Enfermedades de Occidente. Patologías actuales del vacío desde el nexo entre filosofía y psicopatología», en Sáez Rueda, L., Pérez Espigares, P. y Hoyos Sánchez, I. (eds.), Occidente enfermo. Filosofía y Patologías de Civilización. Múnich: Grin, 2011, pp. 77-78.

${ }^{4}$ Nos referimos al carácter simultáneo del ser, entendido como «des-cubrimiento/en-cubrimiento», y la correspondiente «diferencia óntico-ontológica»: «El ser, en el sentido de la sobrevenida que desencubre (entbergenden Überkommnis), y lo ente como tal, en el sentido de la llegada que se encubre (sich bergenden Ankunft) se muestran como diferentes gracias a lo mismo, gracias a la inter-cisión (Unter-schid). La intercisión da lugar y mantiene separado a ese Entre (Zwischen) dentro del cual la sobrevenida y la llegada entran en relación, se separan y se reúnen. La diferencia de ser y ente, en cuanto inter-cisión entre la sobrevenida y la llegada, es la resolución (Austrag) desencubridora y encubridora de ambas. En la resolución reina el claro de lo que se cierra velándose y da lugar a la separación y la reunión de la sobrevenida y la llegada». Heidegger, M.,
«La constitución onto-teo-lógica de la metafísica», en Identidad y diferencia. Barcelona: Anthropos, 1988, p. 134.

${ }^{5}$ Cfr. Espósito, R., Communitas. Origen y destino de la comunidad. Buenos Aires: Amorrortu, 2003, pp. 919.

${ }^{6}$ Cfr. Heidegger, M., Ser y Tiempo. Madrid: Trotta, 2012, pp. 134-145.

${ }^{7}$ Desde su posición privilegiada como miembro fundador del Centro para la Investigación sobre el léxico político europeo emplazado en Bolonia, el pensador napolitano ha firmado una meritoria obra deconstructiva del mismo que demuestra su estratificación de sentido, encarando el desafío hermenéutico que supone resemantizar sus categorías fundamentales («política», «comunidad», «democracia», «soberanía», «violencia», etc.) para esclarecer, desde una perspectiva «impolítica», la constelación actual de sus significados al hilo de los procesos contemporáneos. Cfr. Espósito, R., Categorías de lo impolítico. Buenos Aires: Katz, 2006; Diez pensamientos acerca de la política. Buenos Aires: FCE, 2012.

${ }^{8}$ Heidegger denomina «nihilismo propio» a la radical co-pertenencia entre ser y nada que implica, como envés de su carácter simultáneo, la dimensión abisal del ser (Ab-grund), o sea, el ser se sostiene sobre la nada: «El ser es fondo y abismo, carente de fundamento porque toda fundamentación tendría que deponer al ser hasta hacerlo ente. En la medida en que el ser es fundar no tiene fundamento» Heidegger, M., La proposición del fundamento. Barcelona: Serbal, 1991, pp. 175-176. Ahora bien, la noción heideggeriana de «nada» se desmarca de su acepción cientificista como «lo absolutamente no-ente», ya que es más originaria que la negación y, por consiguiente, trasciende la lógica universal. Cfr. Heidegger, M., «¿Qué es metafísica?», en Hitos. Madrid: Alianza, 2000, pp. 96-97.

${ }^{9}$ Cacciari, M., El archipiélago. Figuras del otro en Occidente. Buenos Aires: Eudeba, 1999, p. 39.

${ }^{10}$ Para matizar esta idea, nos remitimos al análisis del concepto «errático» a cargo de L. Sáez. Cfr. Sáez, L., Ser errático. Una ontología crítica de la sociedad. Madrid: Trotta, 2009, p. 135. A ojos vistas, cabe definir el término «errático», a tenor de su origen latino (erraticus), como «carecer de lugar» y «recorrer a la ventura». En este sentido, la RAE le atribuye los significados siguientes: 1. «Vagabundo, ambulante, sin domicilio cierto». 2. «Errante», en el sentido de una es- 
La comunidad ortopédica. Por una crítica de patologías desde el paradigma inmunológico

trella errante, que significa tanto como planeta (del

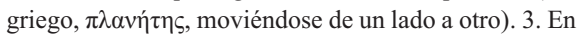
medicina, el término hace referencia a un dolor «crónico», que oscila por el cuerpo sin asiento fijo. Desde otro punto de vista, empero, su significado tiene que ver con la idea de estar discurriendo (por ejemplo, a través del campo, erro in agris), de tal manera que estar errático no implica simplemente encontrarse dislocado sino también incurso en una suerte de ex-tradición nomadológica, esa tensión metamórfica insuprimible simbolizada por Hermes, el dios amigo de los caminantes para el que no existen cerraduras, recinto ni clausura.

${ }^{11}$ Cfr. Sáez, L., Ser errático..., cit., pp. 217-229; 270-297.

${ }^{12}$ Bégout, B., Le ParK. París: Allia, 2010, p. 37.

13 Tanto las representaciones del origen de la humanidad (véase la versión de la mitología clásica o la del génesis en el relato bíblico), como las expresiones culturales más importantes en arte, literatura y filosofía, confirman la conexión intrínseca entre «comunidad» y «violencia», tanto por el carácter común de la violencia como por el carácter violento de aquello que es común. En efecto, todas identifican el corazón negro de la comunidad originaria con su carácter ilimitado, en tanto que la indiferencia (en cuanto ausencia de la línea diferencial que, distanciando a los hombres, los mantiene a salvo de la masacre) la impulsa ineludiblemente hacia el abismo, sin lugares (internos o externos) donde refugiarnos. Cfr. Espósito, R., Diez pensamientos..., cit., pp. 273-278.

${ }^{14}$ Espósito, R., Bíos. Biopolitica y filosofia. Buenos Aires: Amorrortu, 2006, p. 81.

${ }^{15}$ Existen numerosos testimonios «sangrantes» al respecto, en el sentido literal del término. Por ejemplo: en la guerra «humanitaria» de Afganistán (2001), los bombardeos aéreos arrojan simultáneamente víveres y medicinas junto a bombas con un alto poder destructivo sobre los mismos territorios. En Rusia (2002), grupos especiales de la policía estatal provocan, con tal de salvar el mayor número de personas posible, la muerte de 128 rehenes a manos de un comando checheno mediante un gas paralizante de efectos letales. En China (2003), el gobierno central se dedica a vender masivamente sangre extraída a campesinos necesitados de dinero, llenando poblados enteros de seropositivos destinados a morir por falta de medicamentos. Cfr. Ibid., pp. 9-15.

${ }^{16}$ Cfr. Berardi, F., La fábrica de la infelicidad. Madrid: Traficantes de sueños, 2002.

${ }^{17}$ Safranski, R., ¿Cuánta globalización podemos soportar? Barcelona: Tusquets, 2004, pp. 81-82.

${ }^{18}$ Cfr. Arendt, H., Los orígenes del totalitarismo. Madrid: Alianza, 2004, pp. 622-677.

${ }^{19}$ Safranski, R., op. cit., p. 81.
${ }^{20}$ En contraste con la neurosis característica de la sociedad moderna, el fenómeno de la «hiperexpresión» ilustra paradigmáticamente las patologías del vacio que entran y salen, en nuestro presente, por todas partes, en la medida que no se funda en la castración simbólica y, por ende, no puede ser entendido desde la óptica de la supresión, la represión o la renuncia pulsional de las que Freud hablaba, sino que responde a una sobrecarga de estímulos o hiperestimulación comunicativa que lo sitúa en el nivel del just do it, por lo cual posee un carácter psicótico.

${ }^{21}$ Baudrillard, J., La ilusión y la desilusión estéticas. Caracas: Monte Ávila, 1997, p. 12.

${ }^{22}$ Cfr. Heidegger, M., Ser y Tiempo, cit., pp. 186188.

${ }^{23}$ Bataille, G., Sobre Nietzsche. Voluntad de suerte. Madrid: Taurus, 1989, p. 53.

${ }^{24}$ Bayón Martín, F., «La sociedad extrañada: Retóricas de la inmunidad», en Arribas Verdugo, S., Cano Cuenca, G. y Ugarte Pérez, J. (eds.), Hacer vivir, dejar morir. Biopolitica y capitalismo. Madrid: Arbor, 2010, p. 257.

${ }^{25}$ Cfr. Alonso-Fernández, F., Las nuevas adicciones. Madrid: Tea, 2003, pp. 153-173.

${ }^{26}$ Cfr. Heidegger, M., Ser y Tiempo, op. cit., pp. 189-191.

${ }^{27}$ Bayón, F., op. cit., pp. 258-259.

${ }^{28}$ Bodei, R., Destinos personales. La era de la colonización de las conciencias. Buenos Aires: El cuenco de plata, 2006, p. 456.

${ }^{29}$ Polo Blanco, J., «Postmodernidad consumista y nihilismo de la mercancía», Éndoxa: Series Filosóficas, 23 (2009), p. 324. 193.

${ }^{30}$ Cfr. Heidegger, M., Ser y Tiempo, cit., pp. 191-

${ }^{31}$ El espectáculo es la vida en la imagen, una imagen autonomizada cuya puesta en escena, siendo representación de lo real, lo sustituye para ocupar su lugar. Este «simulacro», como Baudrillard lo denomina, se traduce en las variopintas «presentaciones del yo» o el look sin más que cada uno se crea, esto es, la sistematización orgánica y estática, a menudo histriónica, de una auto-ex-posición volcada sobre sus propias inferencias inmanentes, en detrimento del juego de intensidades propio de la praxis social. Convertido en prototipo social, el hombre de farándula autoprotege, de este espurio modo, la evanescencia del estar sobre el «rastro» que implica la «ambigüedad», ese sueño de libertad que enmascara la cruda realidad de la penuria. Cfr. Debord, G., La sociedad del espectáculo. Valencia: Pre-textos, 1999.

${ }^{32}$ Este fenómeno traduce antropológicamente otro con mayor alcance: la metamorfosis moderna de la «forma-mercancía» en la determinación estructural de 
todo lo que es en tanto que es, es decir, la reducción, dicho con la jerga heideggeriana, de todo lo existente a «existencias» (Bestand). Cfr. Polo, J., op. cit., p. 324. Esto es así hasta el punto que los cimientos del «yo», ese edificio tambaleante, llevan hasta sus últimas consecuencias, si bien chapuceramente, la insoportable experiencia de la «erosión del ser», un estallido secular que volatiliza los contenidos hieráticos y monolíticos de manera que nuestros goznes se tornan livianos y caducos (nos «des-quicia»), a costa del desarraigo y la errancia.

${ }^{33}$ Boltanski, L. y Chiapello, E., El nuevo espiritu del capitalismo. Madrid: Akal, 2002, p. 584. Ciertamente, la fluidificación de modelos y criterios, el cultivo de la degustación y, en general, la voluntad de saborear numerosas «vidas paralelas» sin explicitarlas coherentemente, revelan que el ocaso de los valores y su correspondiente desorientación vital (cfr. Ortega y Gasset, J., El tema de nuestro tiempo. Madrid: Espasa Calpe, 1943 ) poseen, en cuanto disgregación orgiástica y fractal, más morbosidad que nunca, ya que un soporte axiológico sólido es conditio sine qua non para orientarse en la vida con equilibrio y salud mental. De aquí se siguen múltiples patologías del criterio pues, en la medida que la inestabilidad y la desconfianza constituyen el humus natural de la existencia, las creencias se truecan modas incapaces de proporcionar, a tenor de su ingravidez, sistemas de referencia a la razón. Además, la inseguridad existencial fomenta la tendencia interna de la sociedad a la hiperfobia, esa sensación velada de catástrofe, inminente pero indeterminada, que flota abstractamente en nuestra conciencia del porvenir.

${ }^{34}$ Sáez, L., «Thanatología del neoliberalismo en el siglo XXI», Otros Logos. Revista de Estudios Críticos, 3 (2008), p. 28.

${ }^{35}$ Espósito, R., Bíos..., cit., p. 11.

${ }^{36}$ Espósito, R., Communitas..., cit., p. 143.

${ }^{37}$ Heidegger, M., Ser y Tiempo, cit., p. 143.

${ }^{38}$ Cfr. Luckmann, T. y Berger, P., «Social Mobility and Personal Identity», European Journal of Sociology, V, 2 (1964), pp. 331-334.

${ }^{39}$ En términos posmodernos, tiene lugar un «ablandamiento» palpable en el ámbito de las ideologías. Escarmentado para depositar su fe en proyectos políticos y desestructurado para involucrarse en una configuración rígida, el ideario del cyborg se reduce a contextos socioculturales restringidos $\mathrm{y}$, por consiguiente, carece de trascendencia incisiva. De aquí el proceso de despolitización en curso, aparentemente imparable, como revelan la indiferencia y la frivolidad que impregnan su estilo de vida, sin pretensiones críticas ni emancipadoras. Prueba de ello es la disolución del «factor subjetivo», al que Marx apelaba como conditio sine qua non de la revolución, en el movimiento socialista, cuyos úl- timos coletazos se difuminan en la absorción irreflexiva del pensamiento crítico en la realidad por la intelligentsia de los rebeldes, en favor de la acción directa e inmediata -sin ideología- ( $c f r$. Marcuse, H., «La relevancia de la realidad», en Bontempo, Ch. y Odell, J. -eds.-, La lechuza de Minerva. Madrid: Cátedra, 1979, pp. 240-242), así como la «autonomización de la vida asamblearia» (cfr. Sáez, L., «Ficcionalización del mundo. Aportaciones para una crítica de patologías sociales», Revista de Filosofia Universidad de Costa Rica, XLV, 115-116 (2007), pp. 62-63) y sus aspavientos fementidos e incoloros: «Reducidas a meros verbalismos fantasmales, [las ideologías] ya no constituyen fieros principios de acción, han dejado de ser operativas en un sentido estricto, sucumben en una mera escenografía superflua dispuesta en el caleidoscopio de las banales etiquetas nominales, en el mero juego lingüístico del trivializado espectáculo político». Polo, J., op . cit., p. 310 .

${ }^{40}$ Sáez, L., Ser errático..., cit., p. 30.

${ }^{41}$ Según Rendueles Olmedo, la creciente tendencia de abordar los problemas colectivos exclusivamente en el nivel de sus consecuencias psicológicas es un correlato de la desactivación de los proyectos radicales de transformación política que involucra la erosión de los vínculos sociales, en tanto que existe cierta retroalimentación entre la economía neoliberal que los fragiliza, la crisis personal de grandes masas de individuos carentes de una red social de referencia y la ampliación ilimitada del radio de acción de la psicología clínica. Santiago Alba no puede mostrarse, en su reseña de Egolatría, más sugestivo al respecto: «La psiquiatrización masiva de la población, de un modo premeditado o no, funciona de hecho como una privatización institucional del conflicto político, mediante la cual se "psicologiza" el paro, el trabajo precario, la explotación laboral y el llamado mobbing o "acoso psicológico" de los empleados. Una sociedad reducida a los puros vínculos privados (contratos bilaterales cada vez más fugaces) y tutelada por una tropilla de mecánicos-psicólogos es una sociedad en la que finalmente (cito experiencias desgraciadamente reales) el sindicato de una empresa defiende a sus afiliados de los malos tratos del jefe costeándole una terapia». Alba Rico, S., «Egolatría», Rebelión (2005) [http://rebelion.org/noticia.php?id=20084].

${ }^{42}$ Luis Sáez explora con tino tal devenir en cuanto «ficcionalización del mundo». Cfr. Ibíd. La condición humana desfallece porque experimenta un vértigo febril que, en realidad, es un movimiento aparente, una administración compulsiva de la carencia apoyada en procesos de clausura y parálisis. En efecto, la actualidad es el espacio de esta «sociedad estacionaria», inmóvil en su movilidad, donde lo genuinamente errático es una ficción vacía, pues la agitación desaforada del hombre no 
La comunidad ortopédica. Por una crítica de patologías desde el paradigma inmunológico

afirma novedades cualitativas con suficiente envergadura para transformar el tablero donde las jugadas se multiplican sin cesar sino que, más bien, aumenta el número de variables y la velocidad de sus desplazamientos en torno a un centro que no deja de repetirse en todos sus rostros.

${ }^{43}$ De aquí se sigue la decadencia de la amistad, formulada en términos de desinterés. Esta concepción de la amistad, relativamente reciente, se remonta a la formación de una filosofía política de la economía, en virtud de la cual cabe pensar un dominio propio completamente regido por la competencia de intereses. La autonomía el interés y de las relaciones interesadas permite distinguir, al menos formalmente, entre dos categorías de relaciones: por una parte, las relaciones de negocios, cuyos socios, por muy cordiales que sean sus vínculos de unión, pueden motivarlos aduciendo la consecución de sus propios intereses (convergentes o competitivos); por otra parte, las relaciones de amistad, perfectamente separadas de cualquier finalidad estratégica y fundadas en gustos comunes. Desde este punto de vista, los juicios morales emitidos en las relaciones personales pivotan sobre dos ejes fundamentales: la «autenticidad», cuando son totalmente gratuitas y la «inautenticidad», cuando algún implicado descubre motivos interesados subyacentes, en lo que constituye el paradigma social de la desilusión y el desencanto. $C f r$. Boltanski, L. y Chiapello, E., op. cit., p. 587.

${ }^{44}$ Elevado sobre un rascacielos de Shangai, el eslogan de Reebok que reza «I am what I am» es paradigmático al respecto, hasta el prurito de expresar, más allá del ideal de una vida lograda por el hecho de cambiar para descubrir y hacer advenir un yo originario, la pura tautología «Yo=yo», el último estadio de la evolución publicitaria tras la mercantilización de la diferencia, la abstracción definitiva. Cfr. Comité Invisible, «Primer cerco. "I am what I am"», Espai en Blanc, 3-4 (2007) [http://www.espaienblanc.net/Primer-cerco-I-AMWHAT-I-AM.html]. Nótese, en otro orden de cosas, que la tensión existente entre la flexibilidad de la identidad posmoderna y la correspondiente mutabilidad de las formas de vida, de un lado, y la necesidad de «ser alguien» (o sea, poseer un yo dotado de una especificidad o «personalidad», así como una permanencia en el tiempo), de otro, constituye actualmente una fuente inagotable de inquietud. Si bien es verdad que el éxito social depende de la plasticidad (en cuanto capacidad, como queda dicho, de tratarnos como un texto traducible a diferentes idiomas para circular a través de lo misceláneo) que mostramos, no deja de ser cierto que, si nos limitamos a ajustarnos a las nuevas situaciones, podríamos pasar totalmente desapercibidos pues, para obtener el reconocimiento de los otros y ganarnos cierta reputación, debemos aportarles algo que sea percibido como característico nuestro, es decir, «ser alguien». En esta tesitura, la posibilidad de encontrar un equilibrio entre la permanencia de sí, siempre amenazada por la rigidez, y la constante adaptación a las demandas contextuales con el riesgo de disolvernos por completo en el tejido de los vínculos transitorios resulta, cuando menos, problemática. Cfr. Boltanski, L. y Chiapello, E., op. cit., pp. 583-586.

${ }^{45}$ Este clima es el caldo de cultivo idóneo del resentimiento, esa pasión miserable cuya genealogía desvela Nietzsche. Toda vez clausurado su ser abierto, el hombre huye del horror vacui creando una identidad que no se funda en su propio caudal sino que se constituye a base de negar, como venganza, enemigos inventados. Y es que cuando la realidad está investida con los galones del bienestar confortable, el malestar no puede ser dirigido contra ella. Cfr. Sáez, L., «Ficcionalización del mundo...», cit., p. 66. Por su parte, además de generar ansiedad y depresión, los niveles actuales de competitividad son especialmente preocupantes en un momento historiográfico donde la agresividad se reproduce por doquier, como atestiguan diversos índices de destructividad; dado que potencia sus bases psicológicas (impulso de autoafirmación exagerado, sobreabundancia de frustraciones y predisposición al miedo y la impotencia), desemboca en episodios violentos a cargo de individuos ávidos por reivindicar su imagen ante sí mismos y los demás. Cfr. Alonso-Fernández, F., Formas actuales de neurosis. Madrid: Pirámide, 1981, pp. 269-274.

${ }^{46}$ Heidegger, M., Ser y Tiempo, cit., pp. 146-147.

${ }^{47}$ Bayón, F., op. cit., pp. 265-266.

${ }^{48}$ Polo, J., op. cit., p. 349.

${ }^{49}$ Según el principio de «destrucción creadora», el «proceso de mutación industrial (si se me permite usar esta expresión biológica) que revoluciona incesantemente la estructura económica desde dentro, destruyendo ininterrumpidamente lo antiguo y creando continuamente elementos nuevos (...), constituye el dato de hecho esencial del capitalismo». Schumpeter, J. A., Capitalismo, socialismo y democracia. Folio: Barcelona, 1984, p. 121. Ahora bien, si bien es cierto que el Capitalismo no puede ser, en cuanto método de transformación económica, estacionario, sus metamorfosis sucesivas no pueden ser entendidas en términos de obsolescencia fulgurante y aceleración disolvente, como quiere Schumpeter, ya que presuponen un engendro en el que la aparición de una nueva cabeza no implica necesariamente la desaparición de los antiguos órganos, de manera que no es tanto un Grossi capitis como una especie de hidra o gorgona. En este sentido, podríamos decir que el Capital cumple el deseo de Ortega para la altura de los tiempos: superar conservando. Cfr. Díaz Galán, J. «"Planet terror”: Esbozo para una tanatopolítica», en Hacer vivir ..., cit., pp. 241-243. 
${ }^{50} \mathrm{Si}$ bien es cierto que, desde sus orígenes, el Capitalismo ha incorporado una exigencia de liberación a su autodescripción, el modo de pervertirla con tal de acompañar y estimular la evolución del proceso de acumulación ha respondido a demandas de autonomía y autorrealización de diversa índole, desde la emancipación de formas especificas de alienación (donde un colectivo situado históricamente padece la opresión de un grupo dominante), hasta la superación de alienaciones genéricas (procedentes del arraigo a un entorno social estabilizado por convenciones, inherentes a la inscripción en un mundo objetivo o a la posesión del propio cuerpo), capaces de limitar la definición de sí de los individuos. Esta perspectiva orienta el proyecto de liberación capitalista en la dirección adoptada por los artistas parisinos durante la segunda mitad del siglo XIX, a saber, la posibilidad de disponer de varias vidas $\mathrm{y}$, correlativamente, una pluralidad de identificaciones adoptadas a modo de «estilos» (looks). Pues bien, según nuestra hipótesis, la actual voluntad re-constructiva que extiende la lógica inmunitaria, con la finalidad de contrarrestar los efectos mortales de la «hiperestimulación semiótica», a niveles donde ni siquiera la «identidad genética» permanece incólume, representa el poste indicador al respecto: «La aspiración de las personas a la movilidad, a la pluralidad de actividades, al ensanchamiento de las posibilidades de ser y de hacer se convierte en una reserva casi ilimitada de ideas a la hora de concebir nuevos productos y servicios para el mercado». Boltanski, L. y Chiapello, E., op. cit., p. 550. Huelga señalar, desde este punto de vista, que si la personalidad se reduce a un cúmulo de piezas desechables y reciclables, también las entrañas de nuestra naturaleza biológica llegarán a ser objeto de manipulación, diseño y consumo.
${ }^{51}$ Aunque la «sociedad del consumo» ha experimentado una miríada de transformaciones gracias al desarrollo del marketing y la publicidad tras la Segunda Guerra Mundial, la crítica marxista de la falacia capitalista de la liberación prometida por medio de su mercado de bienes sigue vigente en la actualidad. Aparentemente libre, el consumidor se encuentra sometido al imperio de la producción, en tanto que sus deseos no emanan de una voluntad autónoma en su irreductible calidad singular sino que, más bien, son el resultado de una manipulación mediante la cual los proveedores de bienes esclavizan su imaginación para determinar la demanda: «La producción no produce solamente un objeto para un sujeto, sino también un sujeto para el objeto». Marx, K., Contribution à la critique de l'économie politique. París: Éditions Sociales, 1957 , p. 157 . No obstante, a pesar de maquillarse con bienes más diversos, menos duraderos y más rápidamente sustituibles con tal de sortear, en virtud de la intuición de los managers de turno para anticiparse a los deseos del público, la saturación de los mercados, la estandarización de los objetos y sus funciones se traduce en una nivelación similar de los usos y, como corolario, de los usuarios, de manera tal que la masificación humana (entendida, en términos de Marcuse en El hombre unidimensional, como «embrutecimiento») es el correlato de la producción en masa (codificada con productos relativamente diferentes pero del mismo estilo), a costa de la libertad ontológica y la responsabilidad existencial de afrontar, en el sentido de la «cura» heideggeriana, la angustia del «ser para sí», en aras de conferir un sentido a la existencia. Testimonio de ello es el caso de las «marcas», entendidas como «etiquetas arbitrarias y manipulables» destinadas a desencadenar «reflejos condicionados». Cfr. Horkheimer, M. y Adorno, T. W., La dialectique de la raison. París: Gallimard, 1974, pp. 173-174. 